\title{
Aproximações à máquina capitalista ${ }^{1}$
}

\author{
Aproximations to the capitalist machine
}

\author{
FÁBIO BATISTA
}

\author{
ESTER MARIA DREHER HEUSER
}

\begin{abstract}
Resumo: Orientado pela filosofia de Deleuze e Guattari, este artigo ocupa-se da máquina capitalista civilizada. De um lado, aborda as relações entre capitalismo - o "inominável" -, psicanálise e Estado; de outro, apresenta possíveis linhas de fuga a esta articulação dominante. Para tanto, reporta-se, também, ao pensamento de Allen Ginsberg e Nietzsche. O artigo defende que, ainda que o "inominável" expanda os seus limites, é do interior dele mesmo que se traçam as linhas de fuga que lhe escapam, pois algo sempre foge e faz fugir.

Palavras-Chave: Capitalismo. Desejo. Linhas de fuga.
\end{abstract}

Abstract: Guided by Deleuze and Guattari's philosophy, this paper focuses on the civilized capitalist machine. On the one hand, it approaches the relations between capitalism - the "unnamable" -, psychoanalysis and State; on the other hand, it presents possible lines of flight from this prevailing articulation. In order to do that, it also resorts to Allen Ginsberg and Nietzsche's thought. The paper advocates that, despite the expansion of the frontiers of the "unnamable", it is from within itself that the lines of flight are traced, since something always escapes and makes escape.

Keywords: Capitalism. Desire. Lines of flight.

Em uma de suas aulas sobre O Anti-Édipo, Deleuze (2005) afirma que uma sociedade não teme o vazio, a penúria ou a escassez, mas o "dilúvio", a afluência impetuosa, os fluxos que passam sobre ela. O dilúvio, neste caso, é aquilo que corre livremente, que não está codificado e aparece como não codificável em relação a uma determinada formação social. Nos movimentos que Deleuze e Guattari (2010) fazem ao tratarem de uma história universal, abordam o que cada uma das três formações sociais que dividem essa história faz para impedir que os fluxos corram livremente, a saber: por temer os fluxos livres, a máquina territorial selvagem codifica seus fluxos em favor da Terra; a máquina despótica bárbara os sobrecodifica a serviço dos desejos do Déspota; a máquina capitalista civilizada, por sua vez, ao ser composta pela conjunção de fluxos descodificados e desterritorializados, assenta-os sobre a produção, num "produzir por produzir" (DELEUZE; GUATTARI, 2010, p. 298), e os conecta ao Capital, o novo corpo pleno desterritorializado.

A máquina capitalista que nos coube viver não mais codifica nem sobrecodifica os fluxos, mas os axiomatiza para deles extrair mais-valia, o seu método para

\footnotetext{
${ }^{1}$ Este texto foi apresentado em Porto Alegre, no Seminário Especial do Programa de Pós-graduação em Educação da Universidade Federal do Rio Grande do Sul (UFRGS) "O Anti-Édipo: uma criança não brinca só de papai-mamãe", promovido pela Linha de pesquisa "Filosofias da diferença e educação", em 20 de maio de 2016. Nesta data, muitas escolas públicas do Rio Grande do Sul estavam ocupadas por estudantes que reivindicavam o direito à participação nas decisões das políticas educacionais.
} 
acumular capital. Assim, podemos dizer que o grande axioma desta máquina é "produção de mais capital". Todos os demais axiomas criados sobre os fluxos funcionarão em favor dele, "em proveito do sistema capitalista e a serviço dos seus fins" (DELEUZE; GUATTARI, 2010, p. 310). Esse grande axioma faz com que todos os desejos, mesmo aqueles da criatura mais desfavorecida, sejam investidos no conjunto do campo social capitalista.

Acima de tudo, os investimentos do Capital estão a serviço do "fim supremo do capitalismo, que é o de produzir a falta onde há sempre excesso" (DELEUZE; GUATTARI, 2010, p. 313). Ou seja, interessa ao capitalismo limitar o desejo e pensa-lo como falta, daí podermos afirmar que a psicanálise é um braço do capitalismo, que ela lhe cai muito bem. Isto não só porque o dinheiro tem um importante papel na psicanálise, porque ela funciona como a máquina capitalista, com a ajuda da dupla face do dinheiro: os fluxos de financiamento e os fluxos de renda (DELEUZE, 2005, p. 86-87), mas também porque a psicanálise faz do desejo (que é o próprio excesso) um problema da vida privada, o aprisiona na família - que foi privatizada no novo socius ${ }^{2}$, posta para fora do campo social - e o impede de abrir-se para investimentos que abranjam o campo social e histórico ${ }^{3}$. Justamente a operação que a Esquizoanálise vai

${ }^{2} \mathrm{O}$ socius, em uma sociedade, é a superfície sobre a qual correm os fluxos, na qual eles são cortados: "[...] socius, que pode ser o corpo da terra, ou o corpo despótico ou, então, o capital. É dele que Marx diz: não é o produto do trabalho, mas aparece como seu pressuposto natural ou divino" (DELEUZE; GUATTARI, 2010, p. 22). Assim a cada máquina corresponde um tipo de socius-superfície para a operação de corte-fluxo.

${ }^{3} \mathrm{Na}$ aula de 16 de setembro de 1971 Deleuze (2005, p. 30) mostrará como a psicanálise e o capitalismo andam juntos e reterritorializam os fluxos descodificados e desterritorializados. Destacamos, especialmente, como eles operam, sobretudo como a psicanálise favorece o êxito da axiomática capitalista: ela reterritorializa os investimentos libidinais do desejo sobre a territorialidade edípica (triângulo familiar; o divã); o capitalismo reinventa territorialidades artificiais para inscrever as pessoas, para tornar vagamente a recodificá-las; para inscrever as pessoas no universo privado inventase qualquer coisa, inclusive políticas econômicas que favoreçam a população de baixa renda quando lhes dá condições de financiar habitação, etc, pois importa a territorialização familiar. Isto porque a família é, apesar de tudo, a célula social, na qual se reterritorializará o bom homem por meio da psiquiatria comunitária. O ponto chave da crítica de Deleuze à psicanálise é que ela funciona a serviço da máquina capitalista na medida em que elimina toda relação com o Fora, aquilo que não está codificado. Com ela, de mãos dadas com o capitalismo, o inconsciente produtivo, o desejo, o delírio se assentam sobre a vida que se passa em família. Enquanto isso não mudar, tudo não passará de um eterno teatro, uma cena que se repete, uma representação do Mesmo que retorna sempre sobre a mesma máscara: Édipo e a castração. Sempre conduzidos à velha estrofe: papai-mamãe-eu. Ocorre, no entanto, que para a psicanálise não há saídas enquanto os psicanalistas não tiverem ouvidos para o Fora, para aquilo que é dito para além de papai-mamãe. O delírio mundial será ignorado por completo enquanto apenas o aparentemente familiar for ouvido. Na entrevista "Sobre o capitalismo e o desejo" (2006), Deleuze relata um caso que se passa no divã e expressa os "ouvidos moucos" do psicanalista para aquilo que ultrapassa, escapa, a família: "Eis um caso. Uma mulher chega para uma consulta. Ela explica que toma tranquilizantes. Pede um copo com água. Depois fala: 'Compreende, tenho uma certa cultura, estudei, gosto muito de ler, e no entanto, neste momento passo meu tempo a chorar. Já não posso suportar o metrô... Eu choro mal leio qualquer coisa... Vejo a televisão, vejo as imagens do Vietnã, já não posso suportar...' O médico não responde grande coisa. A mulher prossegue: 'Fiz a Resistência... um pouco: fui caixa para as cartas'. O médico pede uma explicação. 'Sim, não compreende, doutor? Chegava a um café e perguntava, por exemplo: há qualquer coisa para René? Davam-me uma carta para transmitir...' O médico houve “René”, desperta: “Porque é que disse René?” É 
promover, orientada pela perspectiva histórica de que o campo social e o histórico, aliada aos investimentos sociais é que são primeiros em relação ao pai, à mãe e ao filho.

Em suma, do ponto de vista do socius, seja ele qual for, trata-se sempre de dar uma direção aos fluxos, ou bloqueá-los, é preciso recalcar os fluxos do desejo que circulam livremente, pois uma sociedade teme aquilo que corre e jorra impetuosamente, aquilo que pode levá-la à morte. Vejamos como isso se dá no caso da máquina capitalista civilizada.

A emergência da máquina capitalista, de acordo com Deleuze e Guattari (2010), não se deu de um só golpe, tal como aconteceu com a máquina despótica bárbara, ela teve outro começo. Se a Bárbara é máquina sincrônica - chega de uma só vez e pronta, como Urstaat -, a máquina capitalista é diacrônica. Embora a formação da máquina capitalista implique uma longa história, pois se trata de uma máquina diacrônica, nada nela há de necessário, sua história e formação são frutos da contingência e do acaso. Ou seja, aquilo que é poderia não ser. $\mathrm{O}$ capitalismo não foi algo automático, natural e necessário decorrente do Feudalismo. Por essa razão cabe questionar: já que é, como se tornou possível? Como a máquina capitalista civilizada pôde nascer? Será através da genealogia, que investiga os começos, a baixa origem, que Deleuze e Guattari proporão uma perspectiva a esta questão.

Pensam Deleuze e Guattari que aquilo que está no começo do capitalismo é a descodificação de fluxos. Mas é importante destacar: não é o capitalismo que descodifica os fluxos, os fluxos se descodificam sobre a ruína e a decadência dos grandes impérios (Império Romano, Bizantino, por exemplo). Mais ainda: o capitalismo não procede à descodificação desses fluxos porque, em seu surgimento, supôs fluxos que haviam perdido seus códigos e que, por meio do acaso do encontro, se juntaram. Esses fluxos são:

Fluxo de propriedades que se vendem, fluxo de dinheiro que escorre, fluxo de produção e de meios de produção que se preparam na sombra, fluxo de trabalhadores que se desterritorializam: será preciso o encontro de todos esses fluxos descodificados, sua conjunção, a reação de uns sobre os outros, a contingência deste encontro, desta conjunção, [...], para que o capitalismo nasça [...] (DELEUZE; GUATTARI, 2010, p. 297).

Diante desse quadro poderia se pensar que houve um momento em que os fluxos se descodificaram e tudo esteve livre, e depois teria ocorrido uma recuperação,

a primeira vez que se interessa por uma questão. Até aqui ela tinha falado do metrô, de Hiroshima, do Vietnã, do efeito que tudo isso lhe provocava no seu corpo, o seu desejo de chorar. Mas o médico pergunta apenas: “Olha, olha, René... o que é que René evoca?” René, alguém que renasceu? O renascimento? A Resistência nada significa para o médico, mas renascimento entra no esquema universal, o arquétipo: 'Você quer renascer'. O médico reencontra-se aí: finalmente, o seu circuito. E força-a a falar do seu pai e da sua mãe” (DELEUZE, 2006, p. 342). 
um retrocesso, o próprio mal. Não foi isso, no entanto, que ocorreu! Não, pois o capitalismo substituiu os velhos códigos das formações sociais anteriores por máquinas de conjugar, por máquinas axiomatizadoras. A descodificação e a axiomatização ocorreram simultaneamente. "Que os fluxos se descodifiquem e que sejam retomados por outra máquina - uma máquina de conjugar os fluxos descodificados - é algo que ocorre simultaneamente" (DELEUZE, 2005, p. 45).

O capitalismo se constituiu quando instaurou uma conjugação dos fluxos descodificados, quando estes entraram como tais em uma relação determinável. O campo social pré-capitalista, no qual o capital mercantil ou financeiro estava em aliança com a produção não capitalista ${ }^{4}$, se descodificou por todos os lados e, assim, os fluxos fugiram sob a forma de séries de fugas independentes.

Foi preciso a conjunção de fluxos para que o capitalismo se efetivasse. Ele só surgiu quando dois fluxos descodificados se conjugaram: o fluxo descodificado do dinheiro e o fluxo desterritorializado do trabalho. Dinheiro e trabalho conjugados foram a condição de efetividade do capitalismo. Portanto, se encontram cara a cara, no mercado, o possuidor de dinheiro - que se tornará capital por esta conjunção - e o grande desterritorializado que só possui a força de trabalho, a qual será doravante comprada por um salário (Cf. DELEUZE, 2005, p. 61-62). Esse encontro é o que permitirá que o capital deixe de ser capital de aliança para devir capital filiativo, na medida em que "dinheiro engendra dinheiro, ou o valor uma mais-valia" (DELEUZE; GUATTARI, 2010, p. 302) 5 .

O fluxo descodificado do dinheiro e o fluxo desterritorializado do trabalho são duas séries independentes. Por essa razão, o encontro entre eles poderia não ter acontecido. Na Roma antiga, em um certo momento, se produziu a descodificação do dinheiro e dos trabalhadores, mas eles não se conjugaram e, por isso, não nasceu, naquele momento, o capitalismo. Existe, portanto, uma contingência radical que só é possível ser observada retrospectivamente. De modo muito aligeirado, pode-se dizer que o encontro entre o fluxo descodificado de dinheiro e o fluxo de trabalhadores desterritorializados se deu em um momento em que existiu o interesse em se vender

\footnotetext{
4 "Antes havia capital, mas não no sentido do capitalismo. Havia capital mercantil (comercial) e capital bancário, mas funcionavam unicamente - segundo a bela fórmula de Marx - nos poros da antiga formação. Que quer dizer isto? Estritamente falando, quer dizer que funciona como capital de aliança com a antiga formação pré-capitalista - seja a feudal ou a despótica. Por exemplo, no Império chinês existe todo um capital mercantil e um capital bancário que funcionam na aliança com esta antiga formação pré-capitalista, com tudo o que isso implica de vigilância, de poder de Estado, de grande déspota" (DELEUZE, 2005, p. 62).

5 "Quando as duas séries de fluxos descodificados se encontram produz-se uma espécie de mutação do capital, que devém capital industrial. Esta mutação é a transformação do capital de aliança em um capital que deve ser chamado de filiação. Em uma bela passagem do livro I de $O$ Capital, a sessão intitulada 'A fórmula geral do capital', Marx mostra esta transformação pela qual o valor nos é apresentado subitamente como uma substância motriz para a qual dinheiro e mercadoria (bens com que se comercia) são simples formas. Isto é, o capital mercantil e o capital bancário, mercadoria e dinheiro passaram a serviço dessa nova forma" (DELEUZE, 2005, p. 62).
} 
as propriedades rurais e investir o dinheiro no setor industrial. Isto explica porque a máquina capitalista civilizada não nasceu antes. Pois, para Deleuze e Guattari, não se trata de ausência ou insuficiência de máquinas técnicas, trata-se somente do não encontro anterior, ou, se quisermos, do desencontro, e, posteriormente, do encontro contingencial entre esses dois fluxos descodificados e desterritorializados ${ }^{6}$.

Muitos encontros foram necessários para a formação "da coisa, a inominável!" (DELEUZE; GUATTARI, 2010, p. 300). Dessa coisa inominável, nasceu o que Deleuze e Guattari (2010) chamaram de "a Idade do Cinismo" que sucedeu a Idade da Crueldade e a do Terror. O "cinismo" é marcado pelo capital como meio de extorquir sobretrabalho e acumular capital. Eis "a coisa" sobre a qual se inscrevem todos os desejos, da qual tentaremos nos aproximar.

Talvez, por termos nascido nesse solo e socius capitalista que deveio diretamente econômico como capital-dinheiro, por estarmos distantes da Idade da Crueldade e do Terror, não percebamos o quão monstruosa e fria é a máquina capitalista civilizada, aparentemente tão branda e tão "civilizada". Mas alguns "loucos" poetas conseguem percebê-lo como essa coisa inominável. É o caso de Allen Ginsberg que pensa o capitalismo, a civilização industrial e a América como o monstruoso Moloch que só tinha sua fúria aplacada quando o fogo de seu ventre devorava recém-nascidos. Não é isso o que faz o capitalismo? Devorar nossas forças? Apropria-se de nossas forças e as fazem funcionar a seu favor? Deixemos falar o poeta:

O Uivo: Uma imagem da coisa!

II

Que esfinge de cimento e alumínio arrombou seus crânios e devorou seus cérebros e imaginação?

Moloch! Solidão! Sujeira! Fealdade! Latas de lixo e dólares intangíveis! Crianças berrando sob as escadarias! Garotos soluçando nos exércitos! Velhos chorando nos parques!

Moloch! Moloch! Pesadelo de Moloch! Moloch o mal-amado!

Moloch mental! Moloch o pesado juiz dos homens!

Moloch a incompreensível prisão! Moloch o presídio desalmado de tíbias cruzadas e o Congresso dos Sofrimentos! Moloch cujos prédios são julgamento! Moloch a vasta pedra da guerra! Moloch os governos atônitos!

Moloch cuja mente é pura maquinaria! Moloch cujo sangue é dinheiro corrente! Moloch cujos dedos são dez exércitos! Moloch

\footnotetext{
${ }^{6}$ Enquanto o código é um sistema de relações que deriva da qualificação dos fluxos determinados por ele, uma axiomática implica uma descodificação generalizada, por isso em seu sistema serão as relações diferenciais entre fluxos que determinarão a qualidade de cada um deles. Por exemplo: antes da conjunção entre os fluxos desterritorializados de trabalhadores e os descodificados de dinheiro não era possível qualificar ambos os tipos, independente e previamente, só a conjunção entre eles, o seu encontro é que permitiu isso. Fora do encontro efetivo não haveria meio de qualificá-los, antes dele o que havia era capitalista virtual e trabalhador virtual que, se não fosse a conjunção, nunca compraria a força de trabalho e nem este venderia (cf. DELEUZE, 2005, p. 122).
} 
cujo peito é um dínamo canibal! Moloch cujo ouvido é um túmulo fumegante!

Moloch cujos olhos são mil janelas cegas! Moloch cujos arranha-céus jazem ao longo de ruas como infinitos Jeovás! Moloch cujas fábricas sonham e grasnam na neblina! Moloch cujas colunas de fumaça e antenas coroam as cidades!

Moloch cujo amor é interminável óleo e pedra! Moloch cuja alma é eletricidade e bancos! Moloch cuja pobreza é o espectro do gênio! Moloch cujo destino é uma nuvem de hidrogênio sem sexo! Moloch cujo nome é a Mente!

[...]

Moloch que penetrou cedo na minha alma! Moloch em quem sou uma consciência sem corpo! Moloch que me afugentou do meu êxtase natural! Moloch a quem abandono! Despertar em Moloch! Luz escorrendo do céu!

Moloch! Moloch! Apartamentos de robôs! Subúrbios invisíveis!

Tesouros de esqueletos! Capitais cegas!

Indústrias demoníacas! Nações espectrais!

Invencíveis hospícios! Caralhos de granito!

Bombas monstruosas!

$[\ldots]$

Desesperos! Dez anos de gritos animais e suicídios!

Mentes! Amores novos! Geração louca!

Jogados nos rochedos do Tempo!

Verdadeiro riso no santo rio! Eles viram tudo! O olhar selvagem! Os

berros sagrados! Eles deram adeus!

Pularam do telhado! Rumo à solidão! Acenando! Levando flores! Rio abaixo! Rua acima!

Ginsberg compreende de que modo nos tornamos servos da máquina capitalista: ela penetrou em nossas almas. Fez do mundo um lugar para si mais do que para nós: concreto, ferro, hospícios, fábricas, pobreza. O que somos nós entre e com tudo isto? Parte do concreto e do ferro, parte da pobreza e da opulência miserável? "Uma consciência sem corpo"? Subjetividade esquálida? Corpo apenas instrumento-veículo de uma subjetividade forjada na incandescência dos infernos moloquianos? Junto ao questionamento do sistema de servidão da máquina capitalista civilizada, compreendemos que o poema de Ginsberg evoca a tarefa éticopolítica que talvez seja a mais elevada. Pois importa, diante daquilo que nos torna escravos, não dobrar-se em reverência, não desejar a vida aprisionada em limites de dor, sofrimento e anestesia: "Eles deram adeus". Importa acima de tudo uma constante "deserção" da máquina capitalista civilizada e a constituição, a criação de modos de vida que possam prescindir do aparato sedativo capitalista: desertar e criar, eis a dupla face do mesmo processo de implosão da máquina capitalista. Uma tarefa coletiva, como observa Ginsberg ao dizer: "Eles...".

O excerto do poema de Ginsberg nos dá uma imagem da máquina capitalista. E aqui a sua poesia torna-se uma importante ponte para a leitura das teses de Deleuze e Guattari. Certamente tal imagem está muito próxima daquilo que os E.U.A. passaram 
na década de 1930, no período pós quebra da Bolsa de Nova York: tempo de crise. Crise do capitalismo que só foi ultrapassada graças à intervenção do Estado na economia: o chamado New Deal (Novo Acordo) que consistiu em investimentos estatais em obras públicas; reforma do sistema bancário e monetário; incentivos agrícolas; criação de medidas voltadas para área social; redução da jornada de trabalho. O New Deal explicita a tese de Deleuze e Guattari acerca da necessidade que o capitalismo tem do Estado: “o capitalismo é capitalismo de Estado". Mas a intervenção estatal norte-americana na economia para salvar o capitalismo só pôde ser bem sucedida na medida em que, para além de propor e implementar as medidas citadas acima, também se apoiou na guerra. Eis a importância, portanto, do complexo político-militar-econômico afirmado pelos filósofos: "O Estado, sua polícia e seu exército formam um gigantesco empreendimento de antiprodução, mas no seio da própria produção, condicionando-a” (DELEUZE; GUATTARI, 2010, p. 314).

Com o capitalismo, o aparelho de antiprodução deixa de ser transcendente ao penetrar em toda a produção e tornar-se seu coextensivo (cf. DELEUZE; GUATTARI, 2010, p. 331). O capitalismo, através das medidas estatais, alarga, por um lado, seus limites, a uma escala sempre mais vasta e, por outro, produz a falta onde há excesso. Essa é sua potência: o poder axiomatizador do capitalismo nunca está saturado, "é sempre capaz de acrescentar um novo axioma aos axiomas precedentes" (DELEUZE; GUATTARI, 2010, p. 332).

Assim, o capitalismo define um campo de imanência e não para de preenchê-lo com "pessoas privadas" - das quais só importam o "seu capital e sua força de trabalho" - e com a "privatização do público" fazendo com que o mundo inteiro se passe em família, a qual, por sua vez, foi posta para fora do campo social por um movimento privatista, mas que se tornará "a condição sob a qual todo o campo social poderá aplicar-se à família” (DELEUZE; GUATTARI, 2010, p. 350) - haja vista as razões familistas apresentadas pelos Deputados Federais para serem favoráveis a abertura do impeachment da presidenta da república: "a conjunção familiar resulta das conjunções capitalistas, uma vez que estas se aplicam a pessoas privatizadas. Papai-mamãe-eu: tem-se certeza de encontrá-los em toda parte, pois que tudo foi aplicado neles" (DELEUZE; GUATTARI, 2010, p. 332). Também na política nacional assistimos horrorizados a cínica "podridão edipiana que se cola à nossa pele" (DELEUZE; GUATTARI, 2010, p. 358).

A hora de Édipo aproxima-se, mas, antes dele o Estado capitalista precisa regular os fluxos e ratificar a falência generalizada dos códigos e das sobrecodificações. É a coisa, o inominável, que avança também através da violência calculada, por meio da racionalidade estatal que regula e organiza as suas falhas, controla a mão de obra e os salários, cria condições favoráveis à acumulação e, assim, se põe a serviço da potência econômica, seja em tempos de crise ou não. $O$ capitalismo não se oporá ao princípio de um controle estatal, desde que seja o Estado 
que lhe convém, o que implica "impedir que fluxos descodificados fujam por todos os cantos da axiomática social” (DELEUZE; GUATTARI, 2010, p. 335-342).

Como convir ao capitalismo? Acrescentando novos axiomas favorecedores da classe dominante, seguidamente resultantes da violência e da opressão do capital que produzem imagens muito bem conhecidas por nós, desse lado do subdesenvolvimento do capitalismo: miséria, desespero e revolta. Imagens que também preencherão o campo de imanência do capitalismo (DELEUZE; GUATTARI, 2010, p. 350). Se, de um lado, os axiomas produzem imagens terríveis como essas, de outro, eles favorecem o socius dinheiro-capital, na medida em que operam a serviço do axioma principal, ou seja, ampliam a produção de capital. A que custo? O da instauração de "uma escravidão incomparável, uma sujeição sem precedente: já não há senhores; agora, só escravos comandam escravos; já não há necessidade de pôr carga no animal de fora, pois ele próprio se encarrega dela" (DELEUZE; GUATTARI, 2010, p. 337). Nietzsche, para nós, expressa essa servidão com seu Zaratustra em "Do novo ídolo" (2003, p. 75):

Estado, chamo eu, o lugar onde todos, bons ou malvados, são bebedores de veneno; Estado, o lugar onde todos, bons ou malvados, se perdem a si mesmos; Estado, o lugar onde o lento suicídio de todos chama-se - "vida"! Olhai esses supérfluos! Roubam para si as obras dos inventores e os tesouros dos sábios; "cultura" chamam a seus furtos - e tudo se torna, neles, em doença e adversidade! Olhai esses supérfluos! Estão sempre enfermos, vomitam fel e lhe chamam “jornal”. Devoram-se uns aos outros e não podem, sequer, digerir-se.

Olhai esses supérfluos! Adquirem riquezas e, com elas, tornam-se mais pobres. Querem o poder e, para começar, a alavanca do poder, muito dinheiro - esses indigentes!

Olhai como sobem trepando, esse ágeis macacos! Sobem trepando uns por cima dos outros e atirando-se mutuamente, assim, no lodo e no abismo.

Ao trono, querem, todos, subir: é essa a sua loucura - como se no trono estivesse sentada a felicidade! Muitas vezes, é o lodo que está no trono - e, muitas vezes, também o trono no lodo.

Dementes, são todos eles, para mim, e macacos sobreexcitados. Mau cheiro exala o seu ídolo, o monstro frio; mau cheiro exala todos eles, esse servidores de ídolos!

Porventura, meus irmãos, quereis sufocar nas exalações de seus focinhos e de suas cobiças? Quebrai, de preferência, os vidros das janelas e pulai para o ar livre!

Fugi do mau cheiro! Fugi da idolatria dos supérfluos!

Fugi do mau cheiro! Fugi da fumaça desses sacrifícios humanos! Também agora, ainda a terra está livre para as grandes almas. Vazios estão ainda, para a solidão a um ou a dois, muitos sítios, em torno dos quais bafeja o cheiro de mares calmos.

Ainda está livre, para as grandes almas, uma vida livre. Na verdade, quem pouco possui, tanto menos pode tornar-se possuído: louvada 
seja a pequena pobreza!

Onde cessa o Estado, somente ali começa o homem que não é supérfluo, ali começa o canto do necessário, essa melodia única e insubstituível.

Onde o Estado cessa - olhai para ali, meus irmãos! Não vedes o arcoíris e as pontes do super-homem?

Assim falou Zaratustra.

Sentimos em Ginsberg e Nietzsche o mesmo tom: ambos apresentam a imagem da máquina capitalista e seu complemento fundamental, o Estado. Em especial vale destacar que ambos também descrevem e advertem sobre o estado exangue da vida sob o capitalismo de Estado. Os dólares inatingíveis tornam a vida um suicídio gradual. A cultura, que poderia nos elevar sempre e sempre, torna-se artificio de supérfluos. O que podemos fazer? Nos dois pensadores, encontramos também, um outro e mesmo tom a ressoar: uma linha de fuga é possível. "Moloch a quem abandono", "eles pularam do telhado". "Fugi do mau cheiro", "ainda a terra está livre para as grandes almas".

Assim, diante do abandono, do pulo, da fuga e da liberdade que nos indicam esses pensadores, o que para nós são propriamente linhas de fuga, perguntamos: poderíamos dizer que quem pouco possui e que não é supérfluo é quem evadiu da escravidão da máquina capitalista? É quem escapou à axiomática e enlouqueceu a máquina? Sim, ao menos é o que nos faz pensar Nietzsche, pois "quem pouco possui, tanto menos pode tornar-se possuído”. Nos parece que são aqueles que, por vezes, só possuem a si mesmos, que evadem na afirmativa e nada doentia viagem esquizofrênica, em direção à abertura. Trata-se, portanto, daqueles que fazem o investimento de desejo de tipo revolucionário: poetas, artistas estão entre eles. Importa também, e especialmente, conceber uma forma coletiva de economia desejante. Ainda que alguns esquizofrênicos não internados, nem adestrados pela química e pela repressão social produzam algo que expresse uma decifração livre do desejo, o problema maior para Deleuze Guattari é "como conceber uma forma coletiva de economia desejante?”. Ao que Guattari responde:

Decerto não localmente. Custa-me muito imaginar uma pequena comunidade liberta que se manteria no meio dos fluxos da sociedade repressiva, como a adição de indivíduos progressivamente libertos. Em compensação, se o desejo constitui a própria textura da sociedade no seu conjunto, inclusive nos seus mecanismos de reprodução, um movimento de libertação pode "cristalizar" no conjunto da sociedade. Em Maio de 1968, a partir de faíscas e choques locais, a perturbação transmitiu-se brutalmente ao conjunto da sociedade, inclusive a grupos que não tinham nem muito nem pouco a ver com o movimento revolucionário, médicos, advogados e merceeiros (apud DELEUZE, 2006, p. 335-336).

O desafio, portanto, nos parece promover a coletividade do desejo 
revolucionário. Dirá Deleuze (2006, p. 300) que "o problema é saber de que maneira 'máquinas' dotadas de uma possibilidade revolucionária vão se agrupar" e levar adiante uma atividade que possa, no próprio âmbito da vida de todos os dias, abrir uma dimensão para uma nova vida. Talvez os jovens que há pouco deixaram a infância e agora ocupam escolas, em São Paulo e no Rio Grande do Sul, e dão lições a nós adultos, estejam constituindo máquinas revolucionárias que vêm burlando o sistema e, por ora, não se deixam axiomatizar. Talvez. Cabe a eles e a nós, se investirmos o desejo em ações coletivas revolucionárias, fazermos a autocrítica do socius capitalista e da miséria do teatro da representação, fazendo-o verter, correr na ordem da produção desejante: eis a tarefa da Esquizoanálise que remete o desejo como produção do real no real ao campo social, fazendo da família uma pequena máquina coextensiva a esse campo.

\section{Referências}

DELEUZE, Gilles; GUATTARI, Félix. O anti-Édipo: capitalismo e esquizofrenia. Trad. Luiz Orlandi. São Paulo: Ed. 34, 2010.

DELEUZE, Gilles. Capitalismo e esquizofrenia (com Félix Guattari). In: A ilha deserta e outros textos. São Paulo, Iluminuras, 2006. p. 295-306.

DELEUZE, Gilles. Sobre o capitalismo e o desejo (com Félix Guattari). In: . A ilha deserta e outros textos. São Paulo, Iluminuras, 2006. p. 331-344.

DELEUZE, Gilles. Derrames: entre el capitalismo y la esquizofrenia. $1^{a}$ edição. Buenos Aires: Cactus, 2005.

GINSBERG, Allen. $O$ Uivo. Disponível em:

$<$ http://anaphylaxxya.blogspot.com.br/2010/o2/o-uivo-parte-i-allen-ginsberg.html>. Acesso em: 16 maio 2016.

NIETZSCHE, Friedrich. Assim falou Zaratustra. Rio de Janeiro: Civilização brasileira, 2003.

Submissão: 26.05.2017 / Aceite: 16.06.2017 